\title{
Trap and release of bisphenol-A, 2-naphthol, and doxepin using a 1- hexadecylamine-copper(II)-amine functionalized indium-tin-oxide electrode
}

Guo-Rong Lin ${ }^{\mathrm{a}}$, John Biechele-Speziale ${ }^{\mathrm{b}}$, Elijah Ernst ${ }^{\mathrm{b}}$, Stuart Burris ${ }^{\mathrm{b}, *}$, Eric D. Conte $^{\mathrm{b}, *}$, Wei-Ping Dow ${ }^{\mathrm{a}}$, Rong-Ho Lee ${ }^{\mathrm{a}}$, Shing-Yi Suen ${ }^{\mathrm{a}, *}$

${ }^{a}$ Department of Chemical Engineering, National Chung Hsing University, Taichung 402, Taiwan

${ }^{\mathrm{b}}$ Department of Chemistry, Western Kentucky University, Bowling Green, Kentucky 42101, USA

* Corresponding authors at Department of Chemistry, Western Kentucky University, USA, and Department of Chemical Engineering, National Chung Hsing University, Taiwan. Tel.: +1270 7452973 (S. Burris) and 7456019 (E. D. Conte); fax: +1740 7456293. Tel.: +886 422852590 (S.-Y. Suen); fax: +886 422854734 .

E-mail address: stuart.burris@wku.edu (S. Burris), eric.conte@wku.edu (E. D. Conte), sysuen@nchu.edu.tw (S.-Y. Suen). 


\section{ABSTRACT}

An electrically controlled and renewable hydrophobic surface used to trap and release three test pollutants on an indium-tin-oxide (ITO) electrode is presented. Oxygen plasma was used to maximize the activated hydroxyl groups on the ITO surface, which were reacted with (3aminopropyl) triethoxysilane (APTES) to create a 3-amino propyl layer. Copper(II) ions were introduced and attached to the terminal amine groups. The amine group from 1-hexadecylamine (HDA), complexed the surface-confined copper(II) ions, which resulted in terminal hexadecyl alkyl groups. The created hydrophobic surface was tested for its ability to adsorb pollutant substances, namely bisphenol-A, 2-naphthol, and doxepin. Desorption was accomplished by reducing copper(II) to copper(0) electrochemically. This led to the weakening of the metal-amine complex and the concomitant detachment of the HDA and trapped species from the ITO surface. Efficient trapping and releasing of bisphenol-A (1 ppm) was achieved with around 84\% adsorption, $100 \%$ desorption (in a time course of less than 30 seconds), and 42-fold enrichment on the concentration. After each adsorption/desorption trial, regeneration of the hydrophobic surface was achieved by reapplication of copper(II) ions and HDA. Five cycles were successfully repeated without any significant deterioration in performance. Similar trap-and-release performance was also attained for 2-naphthol and doxepin.

Keywords:

ITO electrode

Hydrophobic surface

Bisphenol-A

Adsorption

Renewable surface 


\section{Introduction}

The need for environmental remediation strategies continues to grow and thus removal technologies for organic pollutants from water sources have become very important and require continuous improvement. Commonly-used methods for pollutant removal consist of photocatalysis, adsorption, membrane separation, oxidation, electrochemical method, ultrasonication, biological treatment, and other methods [1-4]. Application range, efficiency, cost, and the final form of target species vary with the technique itself. Among these technologies, adsorption is vastly popular because it can be applied to either the enrichment of a dilute species or species recovery for reuse or further processing.

The concentration of dilute pollutants in water typically relies on the design of sorbents. In recent decades, various sorbents have gained considerable popularity for the concentration of contaminant solutes [5-7]. Various styles of sorbents have been tailored to satisfy specific solutes [8]. Due to the advantages of simpler preparation and easier desorption, surfactant-immobilized surfaces and their tailored surface characteristics have attracted the interest of researchers for the concentration of pollutants. Alumina, silica, and ion-exchange resins [9-11] are commonly used as substrates for surfactant attachment. In this regard, most studies have focused on the adsorption of ionic surfactants onto oppositely charged surfaces via electrostatic interactions between the surfactant head groups and substrate.

This study demonstrates that a redox reaction can provide an effective means of electrochemically directing the interfacial adsorption and desorption of surfactant. This electric switching offers a novel tool of desorbing a sorbed solute-surfactant immobilized surface. The surface of indium-tinoxide (ITO) coated glass was modified by forming a layer of 3-aminopropyl triethoxysilane (APTES), which was subsequently modified with 1-hexadecylamine (HDA) surfactant through coordination with copper(II) ions. There are several reports on the use of copper ions as ligand 
linkers on electrode surfaces [12-15]. Recent reports include the electrochemical behavior of bilayers composed of carboxylic-acid and thiol terminated alkyl chains connected on a single $\mathrm{Au}$ electrode [16], and these bilayers sandwiched between Si and Au electrodes [17]. Molecular level manipulation of similar multilayers using Atomic Force Microscopy (AFM) has also been reported [18]. We, however, report the application of trapping and releasing of some hydrophobic solutes by using these types of materials.

The species tested in this study were bisphenol-A, 2-naphthol, and doxepin, which are hazardous materials or PPCPs (pharmaceutical and personal care products) ubiquitous in the environment. As indicated in literature [19-27], these three pollutant species could be adsorbed and removed from water by various sorbents via charge, acid-basic, $\pi-\pi$, or hydrophobic interactions. The sorbents adopted and reported in recent years include specific polymeric adsorbents and membranes [19,22], modified clay materials [3,23-26], surfactant-modified ion-exchange membranes [20,21], molecularly imprinted silica [27], polyaniline-coated $\mathrm{Fe}_{3} \mathrm{O}_{4}$ nanomaterials [4], etc. In the current study, HDA-copper(II)-amine functionalized ITO electrode was employed as the sorbent. After the hydrophobic solutes are adsorbed onto the functionalized ITO electrode, an electrical switch was used to reduce copper(II) ions, resulting in the release of the bound HDA-solute complex. Instead of consuming a large amount of organic solvent to release adsorbed pollutants, using an electric switch to control the release is an environmentally-friendly and time-efficient alternative.

\section{Materials and methods}

\subsection{Materials}

ITO coated glass $\left(90 \% \mathrm{In}_{2} \mathrm{O}_{3}+10 \% \mathrm{SnO}_{2}, 99.9 \%\right.$ purity, $1 \mathrm{~mm}$ thickness) was obtained from Applied Vacuum Coating Technologies (Hsinchu, Taiwan). 3-Aminopropyl triethoxysilane 
(APTES, $98 \%$ purity), cupric chloride $\left(\mathrm{CuCl}_{2}, 99.9 \%\right.$ purity), 1-hexadecylamine (HDA, 90\% purity), bisphenol-A (99.9\% purity), and doxepin hydrochloride (MW 315.8, 98\% purity) were purchased from Sigma-Aldrich (St. Louis, MO, USA). 2-Naphthol (98\% purity) was purchased from Alfa Aesar (Ward Hill, MA, USA). Other chemicals and solvents were of HPLC or analytical grade.

\subsection{Preparation of 1-hexadecylamine-copper(II)-amine functionalized ITO electrode}

The procedures for functionalizing the ITO electrode and the proposed mechanisms are depicted in Fig. 1(a). First, a sample of ITO glass $(1 \mathrm{~cm} \times 2.2 \mathrm{~cm})$ was prepared by sequential ultrasonic cleansing in soapy water (Extran), 2-propanol, n-hexane, and acetone for 10 minutes each. It was dried in an oven at $100{ }^{\circ} \mathrm{C}$. The cleaned ITO was then placed into a plasma chamber and exposed to oxygen plasma at a power of $50 \mathrm{~W}$ for 10 minutes. The hydroxyl groups were oxidized to $\mathrm{O}$ radicals or $\mathrm{O}_{3}$ [28] under this treatment. In a humid environment, the $\mathrm{O}$ radicals or $\mathrm{O}_{3}$ underwent rehydration and became hydroxyl groups again [28]. After these pretreatments, the hydroxyl groups on ITO surface were fully activated (represented as ITO-OP).

Fig. 1. Proposed schemes and mechanisms for (a) the preparation of 1-hexadecylamine-copper(II)amine functionalized ITO electrode; (b) the bisphenol-A adsorption onto the functionalized ITO electrode; (c) the bisphenol-A desorption via electrochemical reduction and the surface regeneration of ITO electrode via electrochemical oxidation plus reapplication of copper(II) ions and HDA.

After oxygen plasma treatment, the ITO sample was immersed in $20 \mathrm{~mL}$ of $100 \mathrm{mM}$ APTES solution (prepared in anhydrous toluene) at proper ambient conditions (relative humidity $<20 \%$ and $70{ }^{\circ} \mathrm{C}$ ) for 6 hours. This step produced the initial 3-amino propyl layer [29,30] (see Fig. 1(a)), which is represented as ITO-APTES. The sample of ITO-APTES was then removed from the solution, 
rinsed with toluene, immersed in toluene, and placed into an orbital shaker for 3 hours. Finally, the ITO glass was rinsed with ethanol and acetone and dried for 12 hours at $60{ }^{\circ} \mathrm{C}$.

After drying, the glass was immersed in $5 \mathrm{~mL}$ of $50 \mathrm{mM} \mathrm{CuCl}_{2}$ (prepared in $95 \%$ ethanol), and placed into an orbital shaker for 3 hours. The glass was rinsed with ethanol three times after copper(II) immobilization (represented as ITO-APTES- $\mathrm{Cu}^{2+}$ ). Next, the sample was placed into 5 $\mathrm{mL}$ of $10 \mathrm{mM}$ HDA (prepared in $95 \%$ ethanol) and placed into an orbital shaker for 12 hours. Finally, the glass was rinsed with ethanol and dried in an oven for 2 hours at $70{ }^{\circ} \mathrm{C}$. This completed the preparation of the 1-hexadecylamine-copper(II)-amine functionalized ITO electrode (ITOAPTES-Cu ${ }^{2+}-$ HDA). The schemes for the above reactions are shown in Fig. 1(a).

\subsection{Characterization of ITO modification}

ATR-FTIR (FTIR-4100, JASCO, Japan) was employed to characterize the functional groups on the ITO electrode surface after each modification step. FE-SEM with EDS (JSM-6700F, JEOL, Japan) was used to examine the 2D morphology of the ITO surface and analyze the elements of the modification layer. The chemical composition on the ITO surface was also analyzed by XPS (PHI 5000 VersaProbe, ULVAC-PHI, Japan). AFM (SPA-400, Seiko, Japan) was applied for investigating the surface roughness. Moreover, the contact angles of water on the modified ITO surfaces were measured using FTA-125, First Ten Angstroms (USA) to evaluate the surface hydrophobicity.

The number of hydroxyl groups on the oxygen plasma-treated ITO sample (ITO-OP) was estimated by cation-exchange capacity measurement. First, one sample of pre-treated ITO glass was immersed in $20 \mathrm{~mL}$ of $0.1 \mathrm{~N} \mathrm{HCl}$ solution for 24 hours at room temperature. This ITO glass was then repeatedly washed with deionized water and equilibrated in $50 \mathrm{~mL}$ of deionized water for 24 hours to remove acid traces. Next, the sample was equilibrated in $50 \mathrm{~mL}$ of $0.01 \mathrm{~N} \mathrm{NaOH}$ solution 
for 24 hours at room temperature. The cation-exchange capacity was determined via back titration using $0.01 \mathrm{~N} \mathrm{HCl}$. Cation-exchange capacity per ITO sample $=\left(\mathrm{M}_{0, \mathrm{NaOH}}-\mathrm{M}_{\mathrm{E}, \mathrm{NaOH}}\right) \times \mathrm{V}$, where $\mathrm{M}_{0, \mathrm{NaOH}}$ and $\mathrm{M}_{\mathrm{E}, \mathrm{NaOH}}$ are the initial and equilibrium concentrations of $\mathrm{NaOH}$ and $\mathrm{V}$ is the volume of $\mathrm{NaOH}$ solution.

Immobilized copper(II) ions were released from the ITO-APTES- $\mathrm{Cu}^{2+}$ glass and measured by chelating with a high-concentration EDTA solution. The copper(II) concentration in the EDTA solution was measured via ICP (715, Agilent, USA).

Bound HDA amount was calculated from the difference between the initial concentration and that remained after the reaction. The HDA concentration was analyzed by HPLC with a RI (refractive index) detector (vide infra).

\subsection{HPLC analysis}

The HPLC system consisted of a Waters 600 Controller pump (USA), a Luna C8 column (5 $\mu$ m, $150 \times 4.6 \mathrm{~mm}$, Phenomenex, USA), a Thermo Finnigan Surveyor PDA (Photo Diode Array) Plus detector (Germany), a Shodex RI-71 detector (Japan), and a computer with chromatographic software. The wavelength used was $280 \mathrm{~nm}$. The mobile phase was acetonitrile:water = 7:3 (v/v), and the flow rate was $1 \mathrm{~mL} / \mathrm{min}$. The column temperature was maintained at $30{ }^{\circ} \mathrm{C}$. The injection volume was $60 \mu \mathrm{L}$.

\subsection{Voltammetric measurement}

Voltammetry was performed on an AutoLab 302 electrochemical workstation (USA). The electrochemical measurements were conducted at room temperature in a single-compartment, threeelectrode quartz-glass cell with a saturated mercury sulfate (SMSE) reference electrode, a sample of 
ITO-APTES-Cu${ }^{2+}-\mathrm{HDA}$ as the working electrode, and a platinum wire as the counter electrode. The electrolyte solution was $0.1 \mathrm{M} \mathrm{KCl}$ in aqueous $5 \%$ methanol solution for copper(II) ion reduction (desorption of adsorbate) and $0.1 \mathrm{M} \mathrm{KCl}$ aqueous solution for copper(0) oxidation (ITO electrode regeneration). The scan range was from -0.8 to $0.8 \mathrm{~V}$ at a speed of $50 \mathrm{mV} / \mathrm{s}$.

\subsection{Batch adsorption/desorption/regeneration cycle}

In the batch adsorption experiment, a sample of ITO-APTES- $\mathrm{Cu}^{2+}$-HDA glass was placed in a container with an aqueous solution of hydrophobic substance (bisphenol-A, 2-naphthol, or doxepin) at certain conditions for $\mathrm{pH}$ and initial concentration. The experiment was carried out at room temperature in a shaker for a period of 6 hours. The scheme for bisphenol-A adsorption is depicted in Fig. 1(b). The concentration of the hydrophobic species in solution was determined by HPLC with a PDA detector. The adsorbed species were quantified by the difference between the amount initially added and the amount remaining in solution after 6 hours.

The ITO glass was then placed in $10 \mathrm{~mL}$ of $0.1 \mathrm{M} \mathrm{KCl}$ in aqueous $5 \%$ methanol solution and scanned from 0.5 to $-0.8 \mathrm{~V}$ at $50 \mathrm{mV} / \mathrm{s}$. This caused the reduction of the copper(II) linker and concomitant desorption of the HDA and adsorbed species from the modified ITO glass. Both the concentrations of the hydrophobic species and HDA in the desorption solution were measured by HPLC with both PDA and RI detectors.

After desorption, the working electrode became ITO-APTES-Copper(0). The copper(0) was reoxidized back to copper(II) by scanning from -0.8 to $0.5 \mathrm{~V}$ at $50 \mathrm{mV} / \mathrm{s}$ in $10 \mathrm{~mL}$ of $0.1 \mathrm{M} \mathrm{KCl}$ aqueous solution. Next, the electrode was regenerated by using the same procedures described in Section 2.2 to re-immobilize copper(II) and HDA. The voltammetric reduction and surface regeneration steps are illustrated in Fig. 1(c).

\section{Results and discussion}


3.1. Characterization of silane, copper(II), and 1-hexadecylamine layer immobilized on ITO surface

The stepwise formation of the hydrophobic ITO glass surface is illustrated in Fig. 1(a). APTES was applied to a hydroxide-activated ITO surface to create an amine-functionalized surface. Copper(II) ion was used to link HDA to the amine-functionalized surface through a Lewis acid-base interaction. Several characterization methods were used to investigate the success of each modification step and quantify the amount of the functional groups on the ITO surface.

ATR-FTIR spectral characteristics of ITO, ITO-OP, ITO-APTES, ITO-APTES-Cu ${ }^{2+}$, and ITOAPTES- $\mathrm{Cu}^{2+}$-HDA are shown progressively from top to bottom in Fig. 2. The most prominent features of the spectra were located between 1030 and $1232 \mathrm{~cm}^{-1}$, where $\mathrm{Si}-\mathrm{O}-\mathrm{Si}$ and $\mathrm{Si}-\mathrm{O}-\mathrm{C}$ bonds are reported. After the reaction with APTES, several new peaks appeared. The 1570 and $1647 \mathrm{~cm}^{-1}$ peaks can be attributed to $\mathrm{N}-\mathrm{H}$ stretching and bending, while the 2864 and $2932 \mathrm{~cm}^{-1}$ peaks can be assigned to $\mathrm{C}-\mathrm{H}$ bond stretching. Therefore, the APTES molecules appear to have successfully attached to the surface of the ITO glass. No new absorption peaks were observed after copper(II) immobilization; however, characteristic peaks for APTES were shifted to smaller wavenumbers. Furthermore, the C-H and N-H bands shown in the FTIR spectra for the main functional groups of HDA were remarkably increased, indicating the successful formation of the ITO-APTES-Cu ${ }^{2+}$-HDA electrode.

Fig. 2. ATR-FTIR spectra of the ITO surface after each modification step.

XPS was employed to further evaluate the presence of key elements, such as silicon $\left(\mathrm{Si}_{2 \mathrm{~s}}, \mathrm{Si}_{2 \mathrm{p}}\right)$, carbon $\left(\mathrm{C}_{1 \mathrm{~s}}\right)$, nitrogen $\left(\mathrm{N}_{1 \mathrm{~s}}\right)$, and copper $\left(\mathrm{Cu}_{2 \mathrm{p}}\right)$, after each surface modification step. The results are displayed in Fig. 3. The XPS result of the oxygen plasma-treated ITO was similar to that of the 
pristine ITO, but it exhibited a slightly higher oxygen content (data shown in Fig. S1). The peaks of $\mathrm{Si}_{2 \mathrm{~s}}, \mathrm{Si}_{2 \mathrm{p}}, \mathrm{C}_{1 \mathrm{~s}}$, and $\mathrm{N}_{1 \mathrm{~s}}$ appeared in the XPS spectra of ITO-APTES. This verifies the formation of an APTES layer on the ITO glass. After soaking the APTES-modified electrode in copper(II) ion solution for 3 hours, strong copper peaks were observed at 931.5 and $952 \mathrm{eV}$, which correspond to $\mathrm{Cu}_{2 \mathrm{p} 3 / 2}$ and $\mathrm{Cu}_{2 \mathrm{p} 1 / 2}$, respectively. Fig. 3 shows an increase in the $\mathrm{C}_{1 \mathrm{~s}}$ and $\mathrm{N}_{1 \mathrm{~s}}$ peaks after HDA treatment, indicating the presence of additional carbon and nitrogen atoms from the HDA.

It is also worthy to note that the surface morphology of ITO glass was changed at each individual modification, as observed from the SEM and AFM images of Fig. 4. The surface roughness (Ra) and the pores were increased gradually by coupling APTES, copper(II) ions, and HDA step-by-step on the oxygen plasma-treated ITO surface. The surface porosity estimated from the SEM photo was about $0.15,0.3$, and 0.4 for ITO-APTES, ITO-APTES-Cu ${ }^{2+}$, and ITO-APTES-Cu ${ }^{2+}-\mathrm{HDA}$, respectively. These results reconfirm the successful step-wise modifications.

Fig. 3. XPS spectra of the ITO surface after each modification step.

Fig. 4. SEM $(50000 \times)$ and AFM $2 D$ images of the ITO surface after each modification step.

Furthermore, each step in the modification of the electrode surface was characterized by the contact angle of water using the static sessile drop method. The drop image was stored and an image analysis system was used to calculate the contact angle from the shape of the drop. The data of contact angles for individual steps of modifying the electrode surface are plotted in Fig. 5. The surface contact angle changed with each step of the surface modification. The initial contact angle value of $56.2^{\circ}$ was obtained on the bare ITO-only glass. After cleaning and oxygen plasma treatment processes (ITO-OP), the surface became more hydrophilic. This hydrophilic character of the surface is due to the increased number of activated hydroxyl groups. Under the oxygen plasma treatment, the 
surface hydroxyl groups were oxidized to $\mathrm{O}$ radicals or $\mathrm{O}_{3}$ [28]. An increased oxygen content has been observed through the XPS measurement (Fig. S1). The $\mathrm{O}$ radicals or $\mathrm{O}_{3}$ underwent rehydration in a humid environment and became hydroxyl groups again [28]. A 10 min exposure time is an optimal for the oxygen plasma treatment under $50 \mathrm{~W}$ of plasma power on the ITO surface for activating these surface hydroxyl groups. As further evidence (shown in Fig. S2), the contact angle of water on the ITO surface decreased with the increasing treatment time. The longer the treatment time, the more surface hydroxyl groups were activated. A stable value of contact angle was reached at the treatment time of $10 \mathrm{~min}$. Next, the contact angle value increased to $86.6^{\circ}$ after modifying the ITO-OP with APTES. The great increase in contact angle with respect to the oxygen plasma-treated ITO glass substrate indicates the presence of the hydrophobic alkyl chains of APTES and the increased surface roughness. In the next step of copper(II) ion doping, the ITO surface should become more hydrophilic; however, the value of contact angle was only reduced very slightly. It could be attributed to both the raised surface roughness (refer to Fig. 4) and the possibility of <100\% utilization of APTES amine groups for copper(II) ion binding. The glass electrode surface showed even more hydrophobic character after the coupling of HDA molecules via a Lewis acid-base interaction with surface copper(II) ions. The resulting surface had a contact angle of $116.9^{\circ}$, confirming the formation of ITO-APTES- $\mathrm{Cu}^{2+}-\mathrm{HDA}$.

Fig. 5. Contact angle data of the ITO surface after each modification step.

The number of functional groups created in each individual modification step was quantified in this study. First, the hydroxyl groups on the oxygen plasma-treated ITO glass (ITO-OP) were estimated by the measurement of cation-exchange capacity. The capacity obtained was $12.3 \pm 2.8$ umoles per sample of ITO glass $\left(2.2 \mathrm{~cm}^{2}\right)$. Then, the specific atomic ratios $(\mathrm{C} / \mathrm{N}$ and $\mathrm{Cu} / \mathrm{N})$ for modified ITO samples were calculated from both the EDS and XPS data by using the nitrogen as a 
reference. Those results are shown in Table 1. In the APTES modification step, the measured C/N values are very close to the theoretical value of 3 (i.e. $3 \mathrm{CH}_{2}$ groups and $1 \mathrm{NH}_{2}$ group in one APTES molecule), which indicates a successful formation of APTES layer on the surface. The copper(II) ion immobilization with APTES is about $80 \%(\mathrm{Cu} / \mathrm{N}$ ratio is 0.8$)$, implying that $20 \%$ of amine groups of APTES were not connected with the copper(II) ions. This result of $<100 \%$ utilization authenticates the previous explanation for the slight difference on the surface contact angles between ITO-APTES and ITO-APTES-Cu${ }^{2+}$. The immobilized copper(II) amount was evaluated from the difference in copper(II) concentration before and after the immobilization step; the value is $7.1 \mu$ moles per sample of ITO glass. The utilization of surface hydroxyl groups for copper ion immobilization (immobilized copper(II) capacity/cation-exchange capacity of glass $=7.1 / 12.3$ ) was estimated to be $60 \%$. For an APTES monolayer formation as presented in Fig. 1(a), one hydroxyl group can react with one APTES molecule and one amine group of APTES can bond with one copper(II) ion. Then, the utilization of hydroxyl groups on the ITO glass surface for the APTES reaction should be $75 \%$ (i.e. 60\%/80\%). However, multiple APTES molecular layers may be formed on the hydroxide surface as reported in literature [30].

Table 1 also lists the atomic ratio data for the HDA coupling step where the adsorbed HDA amount was calculated from the difference in concentration before and after the coupling step. The coupled HDA capacity is $7.1 \mu$ moles per sample of ITO glass, identical to the immobilized copper(II) ion amount; this means all available copper(II) ions bonded with HDA. Therefore, for each mole of APTES molecules attached on the surface, 0.8 mole of copper(II) was immobilized, and 0.8 mole of HDA coupled with copper(II). Accordingly, the expected $\mathrm{Cu} / \mathrm{N}$ ratio should be $0.8 /(1+0.8)=0.44$ and the $\mathrm{C} / \mathrm{N}$ value be $(3+16 \times 0.8) /(1+0.8)=8.8$. The measured $\mathrm{Cu} / \mathrm{N}$ ratios shown in Table 1 were slightly lower than the expected value and the measured $\mathrm{C} / \mathrm{N}$ values were higher.

Table 1 Atomic ratio values from EDS and XPS measurements. 


\subsection{Batch bisphenol-A adsorption results}

In the batch adsorption experiment, one sample of the ITO electrode was immersed in $500 \mathrm{~mL}$ of dilute bisphenol-A solution (1 ppm) at room temperature for 6 hours. ITO electrodes with various modification degrees were tested. As seen in Fig. 6, the ITO-APTES- $\mathrm{Cu}^{2+}-\mathrm{HDA}$ adsorbed bisphenol-A at high percentages, approximately $85 \%$ (adsorption $\%=$ adsorbed amount/feed amount $\times 100 \%$ ), while the pristine and oxygen plasma-treated ITO glasses (ITO and ITO-OP) adsorbed only minute amounts of this hydrophobic molecule. The glass electrodes with either amine groups of APTES or copper(II) ions on the surface could also adsorb bisphenol-A, but at low percentages. These results indicate that the bisphenol-A adsorption onto the ITO-APTES- $\mathrm{Cu}^{2+}$-HDA electrode was mainly through the hydrophobic interaction between the long carbon chain of HDA and the intermediate methyl and aromatic groups of bisphenol-A. However, bisphenol-A molecules may simultaneously interact with the free amine groups of APTES via hydrogen bonding.

Fig. 6. Bisphenol-A adsorption percentages of the ITO electrode after each modification step.

The influence of $\mathrm{pH}$ on bisphenol-A adsorption onto the functionalized ITO electrode was also investigated. The $1 \mathrm{ppm}$ bisphenol-A solution without $\mathrm{pH}$ adjustment had a $\mathrm{pH}$ of 6.6. Under the same adsorption conditions, two more $\mathrm{pH}$ values were tested. The bisphenol-A adsorption percentage was reduced to $42 \%$ for $\mathrm{pH} 10$ and $36 \%$ for $\mathrm{pH} 12$. According to the literature [3,4,31], bisphenol-A has $\mathrm{pKa}_{1}$ at $\mathrm{pH}$ 8-9.6 and $\mathrm{pKa}_{2}$ at $\mathrm{pH}$ 9-10.2. At $\mathrm{pH}$ of 6.6 (below $\mathrm{pKa}{ }_{1}$ ) bisphenol-A is neutral $[3,4,32]$, such that it could be adsorbed onto the HDA-coupled ITO surface mainly via hydrophobic interaction. Thus, a high adsorption percentage $(85 \%)$ was obtained at this $\mathrm{pH}$. When the $\mathrm{pH}$ was increased to 10 (in between $\mathrm{pKa}_{1}$ and $\mathrm{pKa}_{2}$ ), bisphenol-A became deprotonated to various anionic forms; whilst it was fully dissociated to divalent anions at $\mathrm{pH} 12$ (above $\mathrm{pKa}_{2}$ ) 
$[3,4,32]$. The anionic charges had significantly affected bisphenol-A adsorption with the immobilized HDA and might even cause the detachment of HDA from the ITO surface by interacting with the copper(II) ions.

Adsorption rate curves of bisphenol-A at various initial concentrations (without $\mathrm{pH}$ adjustment) are presented in Fig. 7. With the pristine ITO glass, the bisphenol-A concentration did not change with time, verifying again that the unfunctionalized ITO electrode did not adsorb bisphenol-A. With the ITO-APTES-Cu${ }^{2+}$-HDA electrode, the bisphenol-A concentration decreased drastically in the first 1-2 hours and then reached a stable concentration at 4-6 hours. The rate curve shapes were similar in all three initial concentration cases. However, the equilibrium bisphenol-A concentration was found at $15 \%, 84 \%$, and $92 \%$ of the original concentration for the case of 1,5 , and $10 \mathrm{ppm}$, respectively. That is, adsorption percentage was $85 \%, 16 \%$, and $8 \%$, respectively. The adsorption equilibrium result for $1 \mathrm{ppm}$ was identical to that shown in Fig. 6. The calculated amount of bisphenol-A removed from the feed solution was very close for each of these three cases, about 1.75-1.85 $\mu$ moles per sample of functionalized ITO (ca. $0.54 \mathrm{~g}$ ). These results indicate that the functionalized ITO electrode prepared in this study is more suitable for the enrichment of dilute bisphenol-A solution.

Fig. 7. Bisphenol-A adsorption rate curves with bare ITO and fully treated ITO.

\subsection{Electrochemical characterization of ITO-APTES-C $u^{2+}-H D A$ glass electrode}

The ITO-APTES-Cu${ }^{2+}$-HDA glass electrode and each step of ITO surface modification were monitored by cyclic voltammetry, as depicted in Fig. 8. The bare ITO glass and ITO-ATPES showed only background current, as expected, when no copper(II) was present. After the copper(II) treatment (vide supra, section 2.2), the response exhibited strongly quasi-reversible behavior with a 
peak potential separation $(\Delta \mathrm{Ep})$ of $0.36 \mathrm{~V}$ and a slightly larger reduction current than oxidation current $(0.08 \mathrm{~mA})$. This indicates probable loss of copper(0) after the reduction and agrees in principle with the $5 \%$ loss of copper experienced in the batch adsorption/desorption cycles described below. With the immobilization of the HDA, the response had an increased peak separation ( $\Delta \mathrm{Ep})$ of $0.4 \mathrm{~V}$ and additional differential between reduction and oxidation peak currents $(0.22 \mathrm{~mA})$. This may be attributed to the formation of an insulating layer of HDA molecules which perturbed the interfacial electron transfer considerably. This indicates an efficient coordinate covalent bonding of HDA through copper ions.

Fig. 8. CV results of the ITO electrode after each treatment modification step.

\subsection{Results for batch bisphenol-A desorption and five adsorption/desorption/regeneration cycles}

After bisphenol-A adsorption $(500 \mathrm{~mL}$ feed of $1 \mathrm{ppm}$, adsorption percentage $=85 \%$ ), the electrode was placed in $10 \mathrm{~mL}$ of $0.1 \mathrm{M} \mathrm{KCl}$ (prepared in aqueous 5\% methanol) and linear sweep voltammetry was performed at $50 \mathrm{mV} / \mathrm{s}$ from 0.5 to $-0.8 \mathrm{~V}$ in order to reduce the copper(II) ions and simultaneously release the HDA layer and the bisphenol-A molecules as illustrated in Fig. 1(c). HPLC analysis was used to determine both the desorbed HDA and bisphenol-A amounts, and they were found to be identical to their coupled and adsorbed quantities on the electrode. That is, $100 \%$ desorption was completed in a time course of less than 30 seconds. Due to the use of a smaller volume for desorption, the concentration ratio (desorbed concentration/feed concentration) for bisphenol-A was 42.5. This enrichment factor is higher than the result (4-28) obtained by adopting molecularly imprinted silica as the sorbent for solid phase extraction of dilute bisphenol-A (0.001 $\mathrm{mM})$ at small volumes (1-10 $\mathrm{mL})$ with a methanol elution [27].

Other desorption methods were also tested in this study. A 6-hour batch process using $10 \mathrm{~mL}$ of 
$60 \%(\mathrm{v} / \mathrm{v})$ aqueous methanol solution resulted in the release of $45 \%$ of the HDA and $88 \%$ of the bisphenol-A. To evaluate the efficiency of the electrochemical method, a desorption using the same solution $(10 \mathrm{~mL}$ of $0.1 \mathrm{M} \mathrm{KCl}$ in aqueous $5 \%$ methanol) for $30 \mathrm{~min}$ was conducted without the voltammetric scan. Less than $5 \%$ of the bisphenol-A was removed from the electrode.

After the desorption process, the electrolyte solution was changed to $10 \mathrm{~mL}$ of $0.1 \mathrm{M} \mathrm{KCl}$. Linear sweep voltammetry was performed at $50 \mathrm{mV} / \mathrm{s}$ from -0.8 to $0.5 \mathrm{~V}$ to re-oxidize the copper(0) to copper(II) ions. The re-oxidized copper(II) ions on the ITO surface were chelated with EDTA solution and measured by ICP. The amount was $6.8 \mu$ moles per sample of ITO glass. Compared to the originally immobilized copper(II) capacity $(7.1 \mu$ moles per sample before the voltammetry process), 5\% of the copper(II) ions were lost. The same linear sweep voltammetry process was repeated twice and an additional 5\% of the copper(II) ions were lost from the electrode. To recoup the lost amount, the electrode was immersed in the copper(II) ion solution as in the initial immobilization procedure. After this copper(II) ion regeneration, the ITO electrode was further regenerated by using the initial HDA coupling procedure, which rendered the surface hydrophobic.

To investigate the re-usability of the APTES- $\mathrm{Cu}^{2+}-\mathrm{HDA}$ functionalized ITO electrode, the adsorption/desorption/regeneration cycle was repeated 5 times. The results for each cycle are listed in Table 2. The modified ITO electrode produced nearly the same bisphenol-A enrichment ratio even after being regenerated 5 times. It was successfully reused without any significant deterioration in performance.

Table 2 Performance using the 1-hexadecylamine-copper(II)-amine functionalized ITO electrode for five consecutive adsorption/desorption/regeneration cycles treating $500 \mathrm{~mL}$ of $1 \mathrm{ppm}$ bisphenol-A aqueous solution in each cycle.

\subsection{Batch adsorption/desorption results for 2-naphthol and doxepin}


In an attempt to verify that the modified ITO electrode would function for other hydrophobic compounds, 2-naphthol and doxepin hydrochloride were used. The same adsorption time and desorption conditions as bisphenol-A were adopted in all the trials. For both species, the feed concentration and volume was $0.4 \mathrm{ppm}$ and $1000 \mathrm{~mL}$, respectively. The 2-naphthol adsorption percentage was $77 \%$ at $\mathrm{pH} 6.8$ (without $\mathrm{pH}$ adjustment) and $18 \%$ at $\mathrm{pH} 10.2$-naphthol, a weak acid like bisphenol-A, is reported to have a pKa near 9.5-9.8 [22,26]. 2-naphthol is deprotonated to an anion at pHs above the pKa and in its neutral form at pHs below the pKa $[4,22,24,26]$. The neutral 2naphthol molecules could be preferably adsorbed with the HDA on the functionalized ITO electrode through hydrophobic interactions. In the case of doxepin, its adsorption percentage was $10.5 \%$ at $\mathrm{pH}$ 6 and $43 \%$ at $\mathrm{pH}$ 10. Doxepin, a basic antidepressant drug, has a pKa between 8 and 10 [20,25]. Its amine groups became protonated at $\mathrm{pH} 6$ to form a cation $[19,20,25]$, which may be repelled by the copper(II) ions. At pH 10, doxepin was in a predominately neutral form and more hydrophobic for adsorption. Moreover, for both pollutant species, 93-98\% desorption was attained by using the electric switch method under a desorption volume of $10 \mathrm{~mL}$. The eventual enrichment factor for the better adsorption condition was: 75 for 2-naphthol $(\mathrm{pH} \mathrm{6.8)}$ and 42 for doxepin ( $\mathrm{pH} \mathrm{10).} \mathrm{This}$ functionalized ITO electrode designed together with an electrochemical "switch" has the potential to concentrate dilute hydrophobic pollutants, such as bisphenol-A, 2-naphthol, and doxepin, from aqueous solutions.

\section{Conclusions}

This study successfully investigated an adsorption/desorption/regeneration process via electrical oxidation/reduction for hydrophobic species removal and concentration. The surface presented here with stepwise and multilayer treatment provides an efficient means to adsorb and then electrically release hydrophobic substances. This new substrate may be applied in the area of water remediation 
for the removal of hydrophobic pollutants. Using an electric switch to control the release of the hydrophobic species provides an environmentally-friend way to perform extractions with less reliance on organic solvents, which are typically required for releasing adsorbed substances during conventional adsorption processes. This approach is also time effective, requiring less than one minute for a complete desorption. Most importantly, the adsorption/desorption/regeneration cycle may be repeated many times with essentially the same performance.

\section{Acknowledgements}

The authors gratefully acknowledge support of this work by the National Science Foundation of the United States through awards 1008356 and 0936693 (WKU) and in part by the Ministry of Education of Taiwan (ATU plan) (NCHU). 


\section{References}

[1] C.-H. Hou, S.-C. Huang, P.-H. Chou, W. Den, Removal of bisphenol A from aqueous solutions by electrochemical polymerization on a carbon aerogel electrode, J. Taiwan Inst. Chem. Eng. 51 (2015) 103-108.

[2] E. Nikfar, M.H. Dehghani, A.H. Mahvi, N. Rastkari, M. Asif, I. Tyagi, S. Agarwal, V.K. Gupta, Removal of bisphenol A from aqueous solutions using ultrasonic waves and hydrogen peroxide, J. Mol. Liq. 213 (2016) 332-338.

[3] Q. Yang, M. Gao, Z. Luo, S. Yang, Enhanced removal of bisphenol A from aqueous solution by organo-montmorillonites modified with novel Gemini pyridinium surfactants containing long alkyl chain, Chem. Eng. J. 285 (2016) 27-38.

[4] Q. Zhou, Y. Wang, J. Xiao, H. Fan, Adsorption and removal of bisphenol A, $\alpha$-naphthol and $\beta$ naphthol from aqueous solution by $\mathrm{Fe}_{3} \mathrm{O}_{4} @$ polyaniline core-shell nanomaterials, Synth. Met. $212(2016)$ 113-122.

[5] J.S. Fritz, Analytical Solid-Phase Extraction, Wiley, 1999.

[6] N.J.K. Simpson, Solid Phase Extraction: Principles, Strategies, and Application, Marcel Dekker, 1998.

[7] D.L. Mayer, J.S. Fritz, Silicalite as a sorbent for solid phase extraction, J. Chromatogr. A 771 (1997) 45-53.

[8] E.M. Thurman, M.S. Mills, Solid-Phase Extraction: Principles and Practice, Wiley, 1998.

[9] F. Augusto, L.W. Hantao, N.G.S. Mogollon, S.C.G.N. Braga, New materials and trends in sorbents for solid-phase extraction, Trends Anal. Chem. 43 (2013) 14-23.

[10] M. Moradi, Y. Yamini, Surfactant roles in modern sample preparation techniques: a review, J. Sep. Sci. 35 (2012) 2319-2340.

[11] S. Gangula, S.-Y. Suen, E.D. Conte, Analytical applications of admicelle and hemimicelle 
solid phase extraction of organic analytes, Microchem. J. 95 (2010) 2-4.

[12] M. Brust, P.M. Blass, A.J. Bard, Self-assembly of photoluminescent copper(I)-dithiol multilayer thin films and bulk materials, Langmuir 13 (1997) 5602-5607.

[13] W. Deng, D. Fujita, L. Yang, H. Nejo, C. Bai, Multilayer formation of copper ions $\left(\mathrm{Cu}^{2+}\right)$ deposited onto self-assembled monolayers of alkanedithiols on Au (111) surfaces, Jpn. J. Appl. Phys. Part 2 39(7B) (2000) L751-L754.

[14] T.A. Daniel, S. Uppili, G. McCarty, D.L. Allara, Effects of molecular structure and interfacial ligation on the precision of $\mathrm{Cu}$-bound alpha,omega-mercaptoalkanoic acid "molecular ruler" stacks, Langmuir 23 (2007) 638-648.

[15] T.L. Brower, M. Cook, A. Ulman, Mixed self-assembled multilayer of 4,4`dimercaptobiphenyl and 1,8-octanedithiol, J. Phys. Chem. B 107 (2003) 11721-11725.

[16] S. Johnson, A. Bronowska, J. Chan, D. Evans, A.G. Davies, C. Walti, Redox-induced conformational change in mercaptoalkanoic acid multilayer films, Langmuir 28 (2012) 66326637.

[17] S. Pookpanratana, J.W.F. Robertson, C. Jaye, D.A. Fischer, C.A. Richter, C.A. Hacker, Electrical and physical characterization of bilayer carboxylic acid-functionalized molecular layers, Langmuir 29 (2013) 2083-2091.

[18] C.I. Drexler, K.B. Moore, C.P. Causey, T.J. Mullen, Atomic force microscopy characterization and lithography of $\mathrm{Cu}$-ligated mercaptoalkanoic acid "molecular ruler" multilayers, Langmuir 30 (2014) 7447-7455.

[19] J. Karppi, S. Åkerman, K. Åkerman, A. Sundell, K. Nyyssönen, I. Penttilä, Adsorption of drugs onto a $\mathrm{pH}$ responsive poly(N,N-dimethyl aminoethyl methacrylate) grafted anionexchange membrane in vitro, Int. J. Pharm. 338 (2007) 7-14. 
[20] S.-M. Hong, S.-J. Chen, H.-C. Chiu, D. Sulejmanovic, E.D. Conte, S.-Y. Suen, Hydrophobic solid phase extraction using n-alkanoic acid-immobilized anion-exchange membranes as adsorbents, Microchem. J. 90 (2008) 129-135.

[21] T.-Y. Wang, G.-L. Chen, C.-C. Hsu, S. Vied, E.D. Conte, S.-Y. Suen, Octadecyltrimethylammonium surfactant-immobilized cation exchange membranes for solidphase extraction of selected phenolic compounds, Microchem. J. 96 (2010) 290-295.

[22] J. Huang, X. Wu, H. Zha, B. Yuan, S. Deng, A hypercrosslinked poly(styrene-codivinylbenzene) PS resin as a specific polymeric adsorbent for adsorption of 2-naphthol from aqueous solutions, Chem. Eng. J. 218 (2013) 267-275.

[23] X. Sun, W. Huang, Z. Ma, Y. Lu, X. Shen, A novel approach for removing 2-naphthol from wastewater using immobilized organo-bentonite, J. Hazard. Mater. 252-253 (2013) 192-197.

[24] Y. Tai, C. Shi, C. Wang, Preparation and characterization of anion-cation organopalygorskite for 2-naphthol removal from aqueous solution, J. Mol. Liq. 195 (2014) 116-124.

[25] T. Thiebault, R. Guégan, M. Boussafir, Adsorption mechanisms of emerging micro-pollutants with a clay mineral: Case of tramadol and doxepine pharmaceutical products, J. Colloid Interf. Sci. 453 (2015) 1-8.

[26] S. Yang, M. Gao, Z. Luo, Q. Yang, The characterization of organo-montmorillonite modified with a novel aromatic-containing gemini surfactant and its comparative adsorption for 2naphthol and phenol, Chem. Eng. J. 268 (2015) 125-134.

[27] X. Hu, X. Wu, F. Yang, Q. Wang, C. He, S. Liu, Novel surface dummy molecularly imprinted silica as sorbent for solid-phase extraction of bisphenol A from water samples, Talanta 148 (2016) 29-36.

[28] D.J. Milliron, I.G. Hill, C. Shen, A. Kahn, J. Schwartz, Surface oxidation activates indium tin oxide for hole injection, J. Appl. Phys. 87 (2000) 572-576. 
[29] S. Flink, F.C.J.M. van Veggel, D.N. Reinhoudt, Functionalization of self-assembled monolayers on glass and oxidized silicon wafers by surface reactions, J. Phys. Org. Chem. 14 (2001) 407-415.

[30] R.M. Pasternack, S.R. Amy, Y.J. Chabal, Attachment of 3-(aminopropyl)triethoxysilane on silicon oxide surfaces: Dependence on solution temperature, Langmuir 24 (2008) 1296312971.

[31] X. Wang, T.-T. Lim, Solvothermal synthesis of $\mathrm{C}-\mathrm{N}$ codoped $\mathrm{TiO}_{2}$ and photocatalytic evaluation for bisphenol A degradation using a visible-light irradiated LED photoreactor, Appl. Catal. B Environ. 100 (2010) 355-364.

[32] I. Bautista-Toledo, M.A. Ferro-Garcia, J. Rivera-Utrilla, C. Moreno-Castilla, F.J. Vegas Fernandez, Bisphenol A removal from water by activated carbon. Effects of carbon characteristics and solution chemistry, Environ. Sci. Technol. 39 (2005) 6246-6250. 


\section{Figure captions}

Fig. 1. Proposed schemes and mechanisms for (a) the preparation of 1-hexadecylamine-copper(II)amine functionalized ITO electrode; (b) the bisphenol-A adsorption onto the functionalized ITO electrode; (c) the bisphenol-A desorption via electrochemical reduction and the surface regeneration of ITO electrode via electrochemical oxidation plus reapplication of copper(II) ions and HDA.

Fig. 2. ATR-FTIR spectra of the ITO surface after each modification step.

Fig. 3. XPS spectra of the ITO surface after each modification step.

Fig. 4. SEM $(50000 \times)$ and AFM 2D images of the ITO surface after each modification step.

Fig. 5. Contact angle data of the ITO surface after each modification step.

Fig. 6. Bisphenol-A adsorption percentages of the ITO electrode after each modification step.

Fig. 7. Bisphenol-A adsorption rate curves with bare ITO and fully treated ITO.

Fig. 8. CV results of the ITO electrode after each treatment modification step. 


\section{Table 1}

Atomic ratio values from EDS and XPS measurements.

\begin{tabular}{lllllllll}
\hline \multirow{2}{*}{$\begin{array}{l}\text { Atomic } \\
\text { ratio }\end{array}$} & \multicolumn{2}{l}{ ITO-APTES } & \multicolumn{3}{l}{ ITO-APTES-Cu ${ }^{2+}$} & \multicolumn{4}{l}{ ITO-APTES-Cu ${ }^{2+}$-HDA } \\
\cline { 2 - 9 } & \multirow{2}{*}{ XPS } & $\begin{array}{l}\text { Theoretical } \\
\text { value }\end{array}$ & EDS & XPS & $\begin{array}{l}\text { Theoretical } \\
\text { value }\end{array}$ & EDS & XPS \\
\hline $\mathrm{C} / \mathrm{N}$ & $3.09 \pm 0.23$ & $2.87 \pm 0.07$ & 3 & $3.12 \pm 0.38$ & $2.75 \pm 0.07$ & 9.5 & $9.11 \pm 0.93$ & $9.98 \pm 0.47$ \\
$\mathrm{Cu} / \mathrm{N}$ & & & 1 & $0.80 \pm 0.03$ & $0.77 \pm 0.05$ & 0.5 & $0.39 \pm 0.07$ & $0.43 \pm 0.12$ \\
\hline
\end{tabular}




\section{Table 2}

Performance using the 1-hexadecylamine-copper(II)-amine functionalized ITO electrode for five consecutive adsorption/desorption/regeneration cycles treating $500 \mathrm{~mL}$ of $1 \mathrm{ppm}$ bisphenol-A aqueous solution in each cycle.

\begin{tabular}{lccccc}
\hline Cycle & 1 st & 2nd & 3 rd & 4 th & 5 th \\
\hline Adsorption \% & 85.2 & 84.7 & 82.6 & 83.8 & 82.1 \\
$\begin{array}{l}\text { Desorption \% } \\
\begin{array}{l}\text { Concentration } \\
\text { factor }\end{array}\end{array}$ & 43.1 & 42.4 & 41.4 & 41.7 & 41.3 \\
\hline
\end{tabular}


(a) Preparation of functionalized ITO electrode

(b) Bisphenol-A adsorption

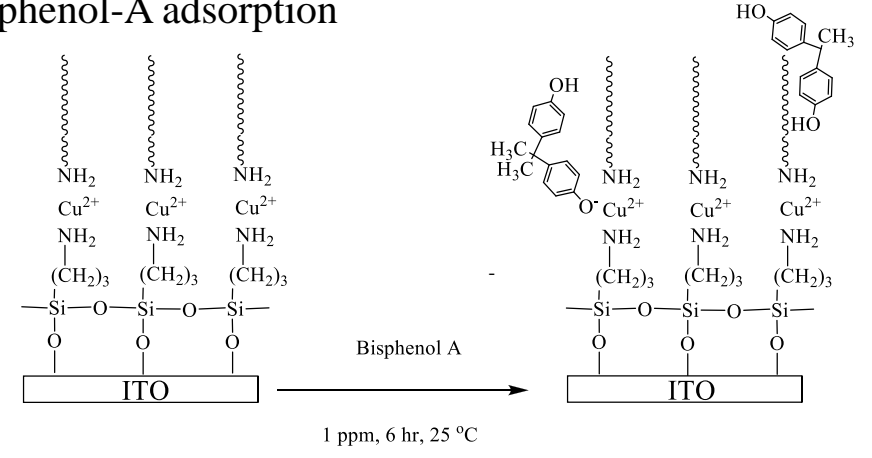

ITO-APTES-Cu ${ }^{2+}$-HDA

(c) Bisphenol-A desorption and ITO surface regeneration
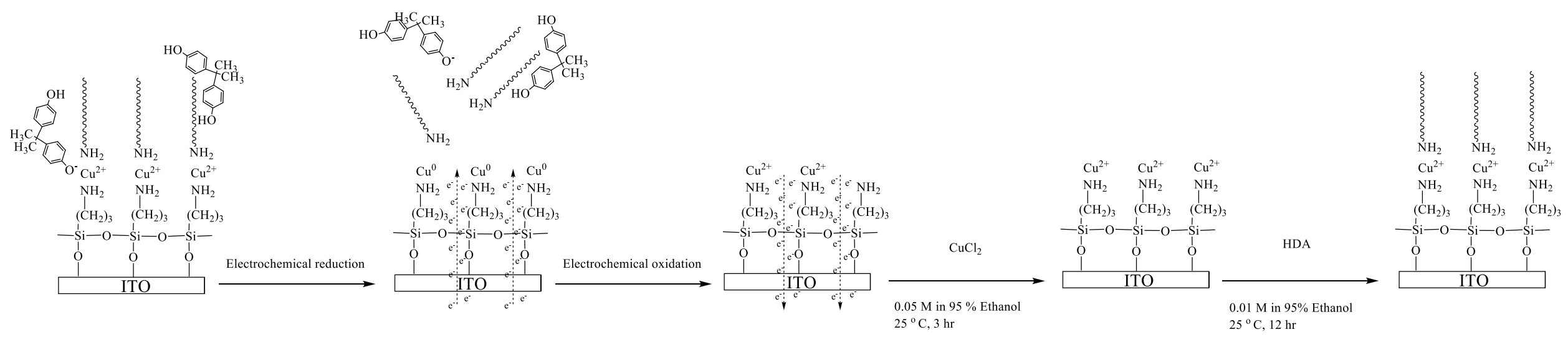

Fig. 1. 


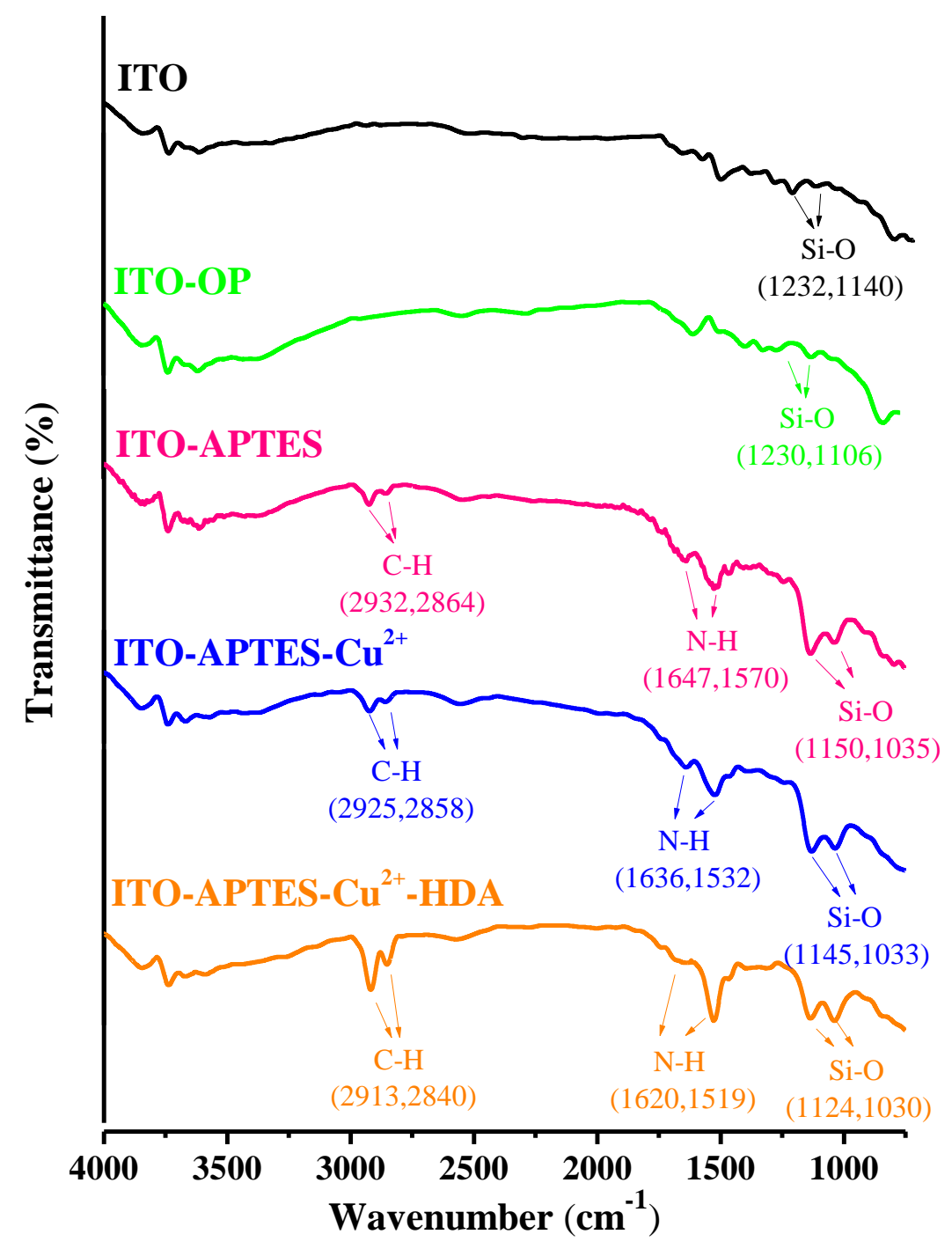

Fig. 2. 


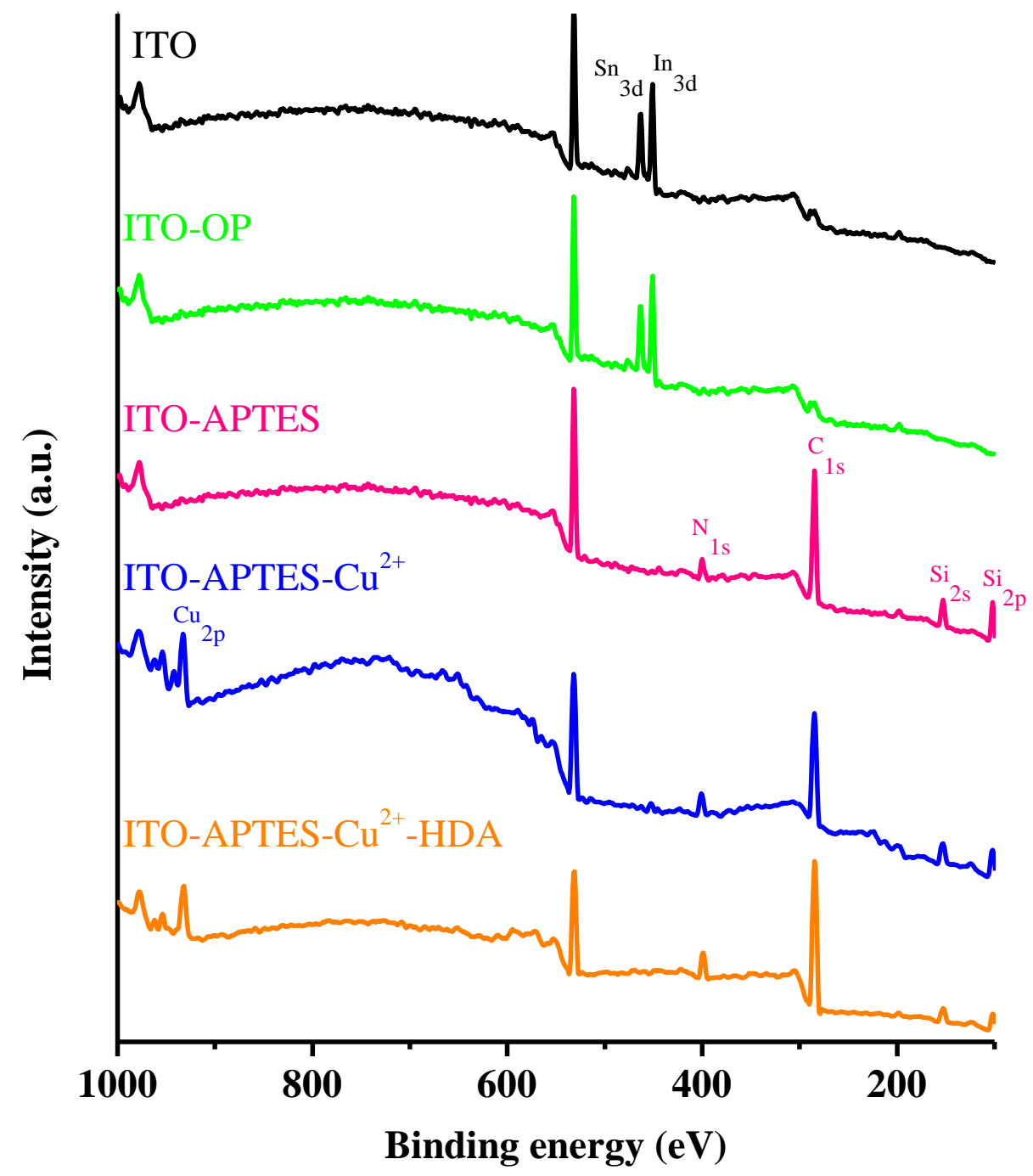

Fig. 3. 
ITO
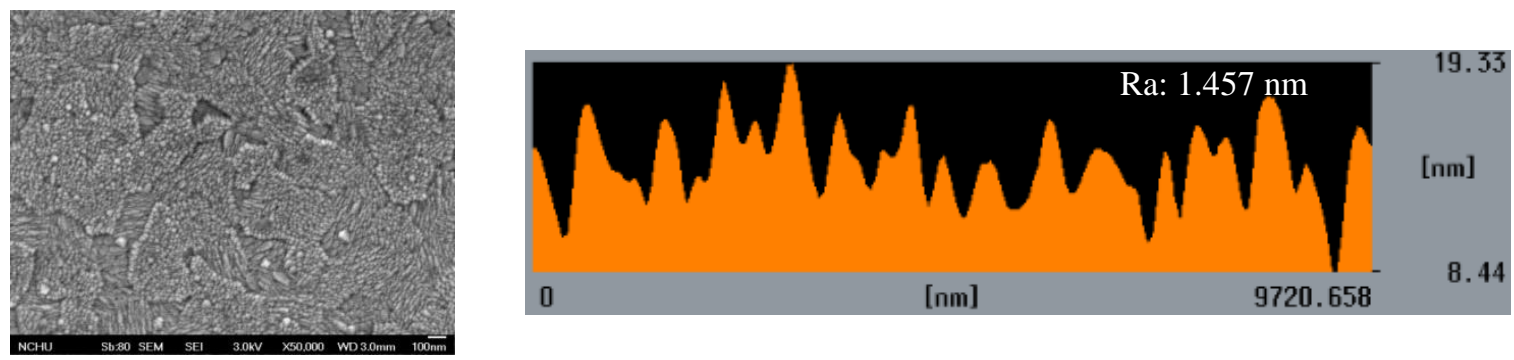

ITO-OP
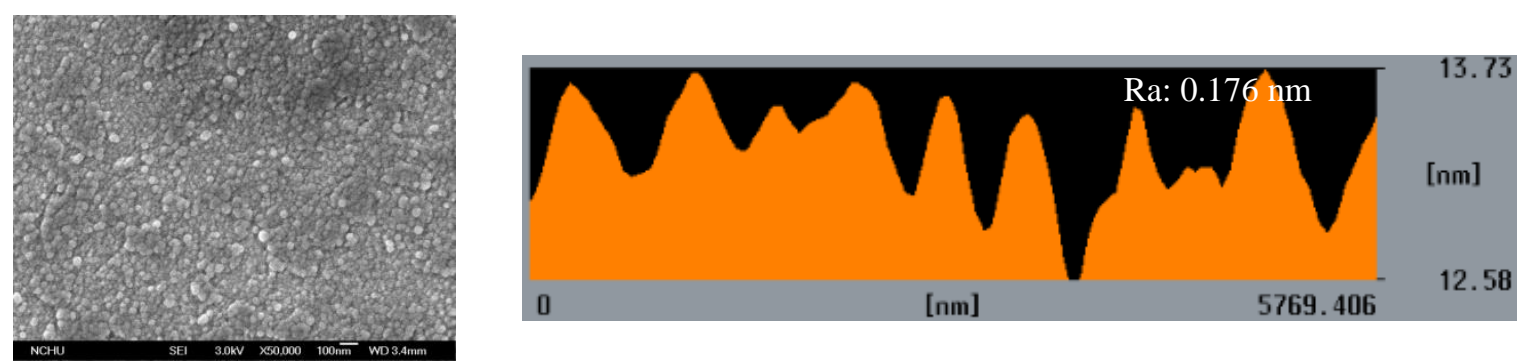

ITO-APTES
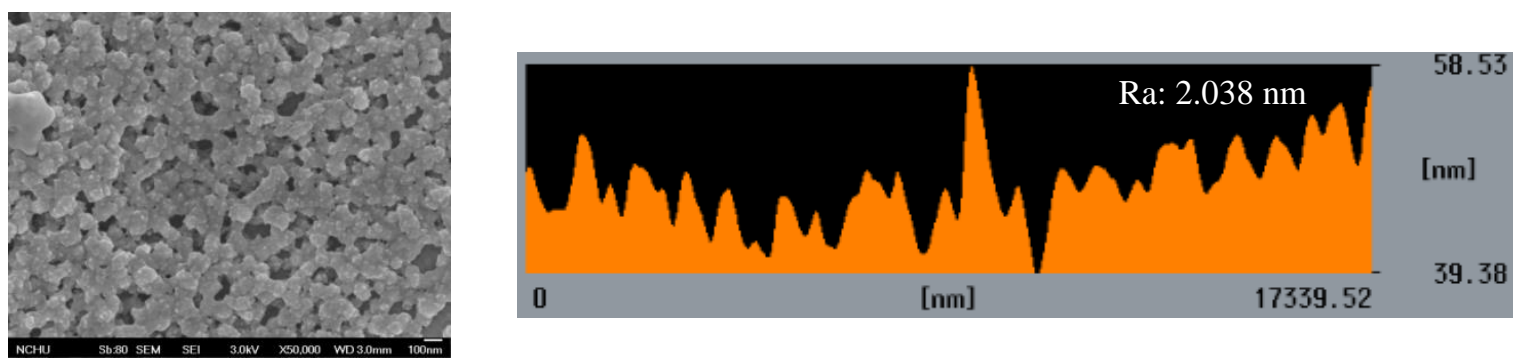

ITO-APTES-Cu ${ }^{2+}$
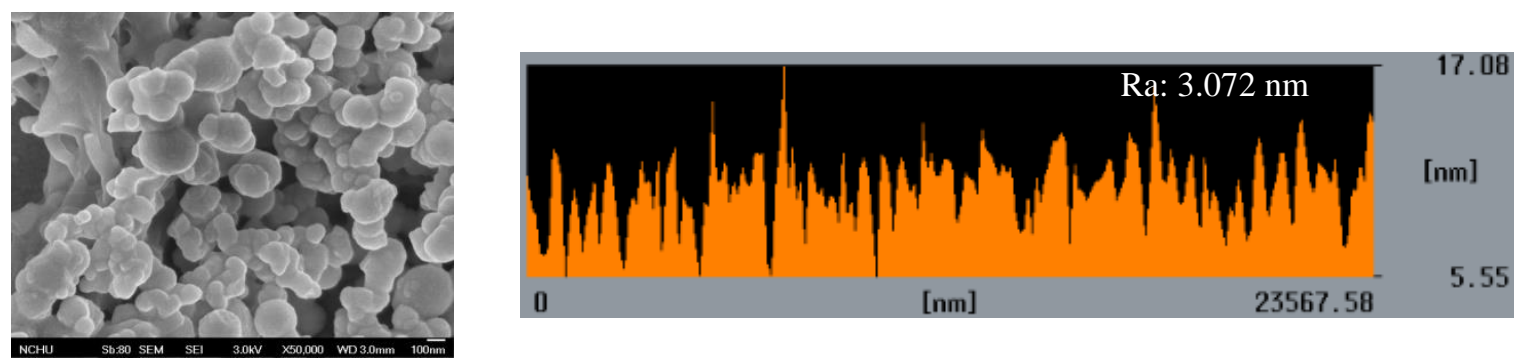

ITO-APTES-Cu ${ }^{2+}-\mathrm{HDA}$
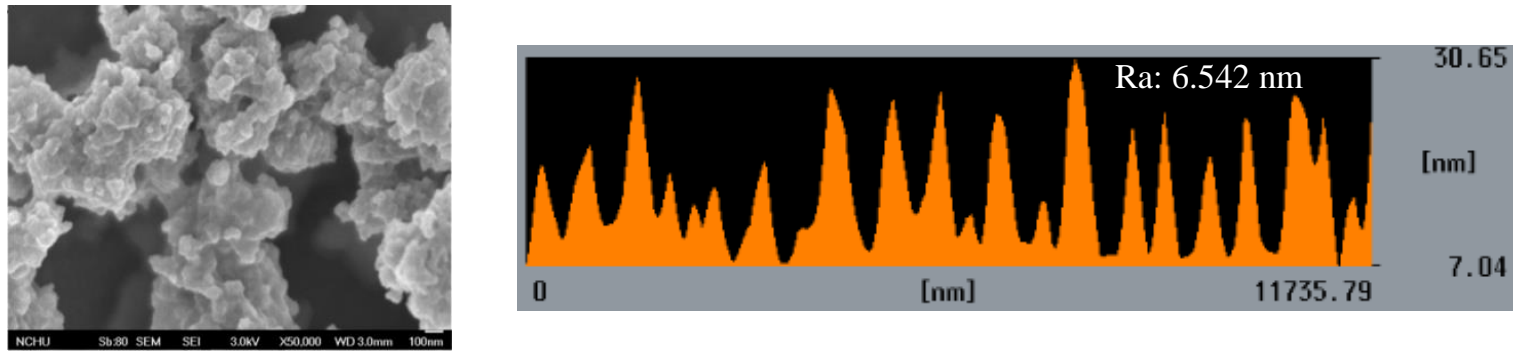

Fig. 4. 


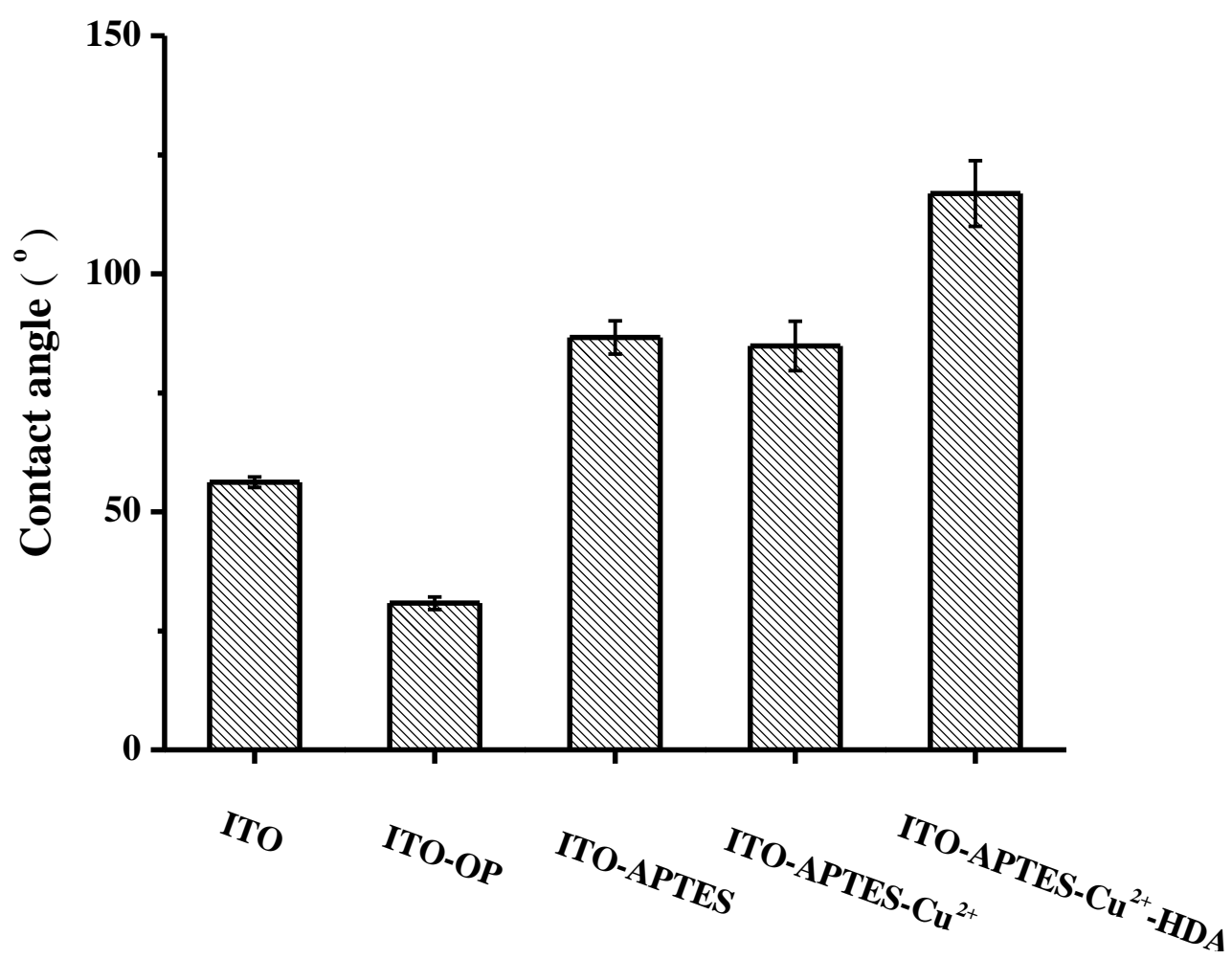

Fig. 5. 


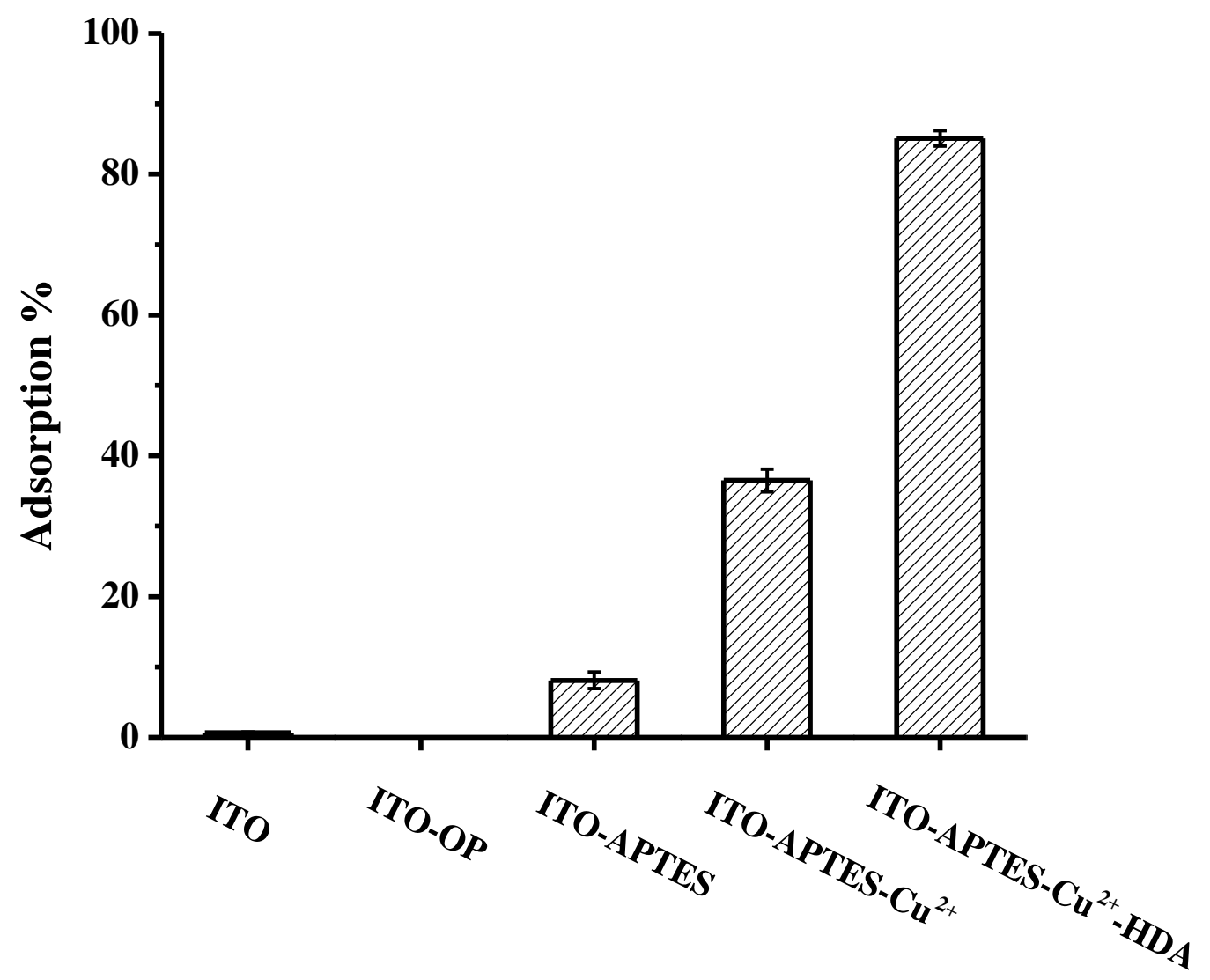

Fig. 6. 

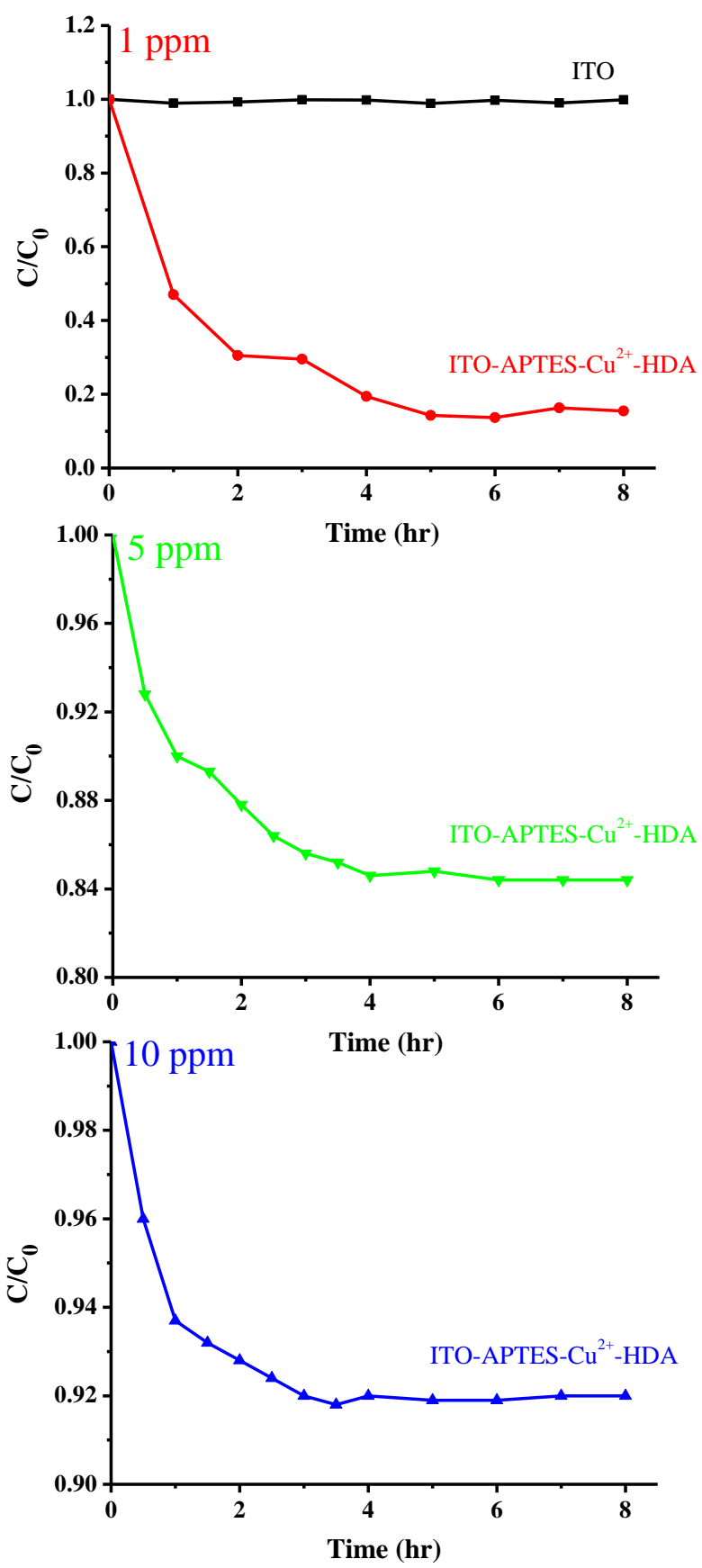

Fig.7. 


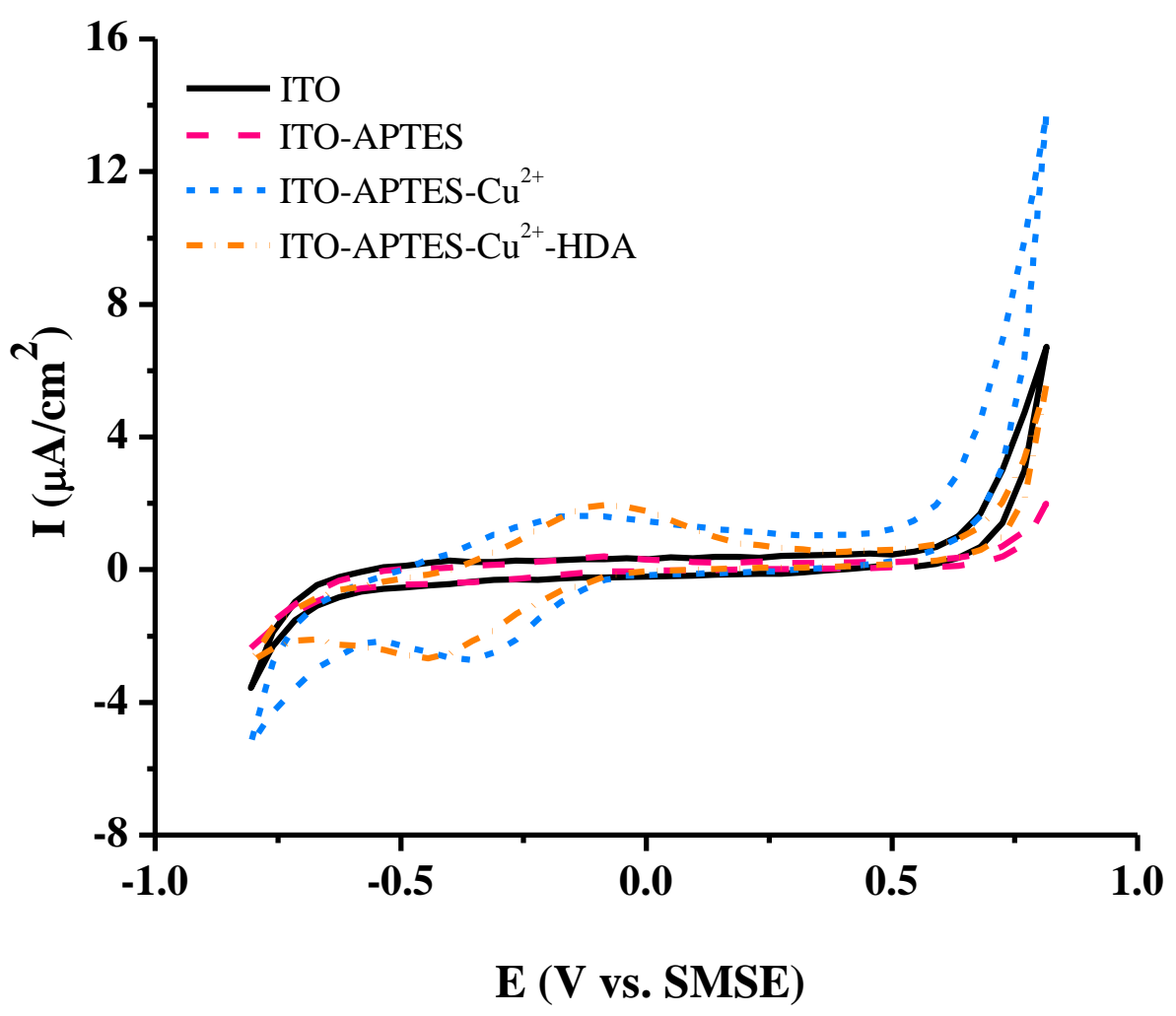

Fig. 8 


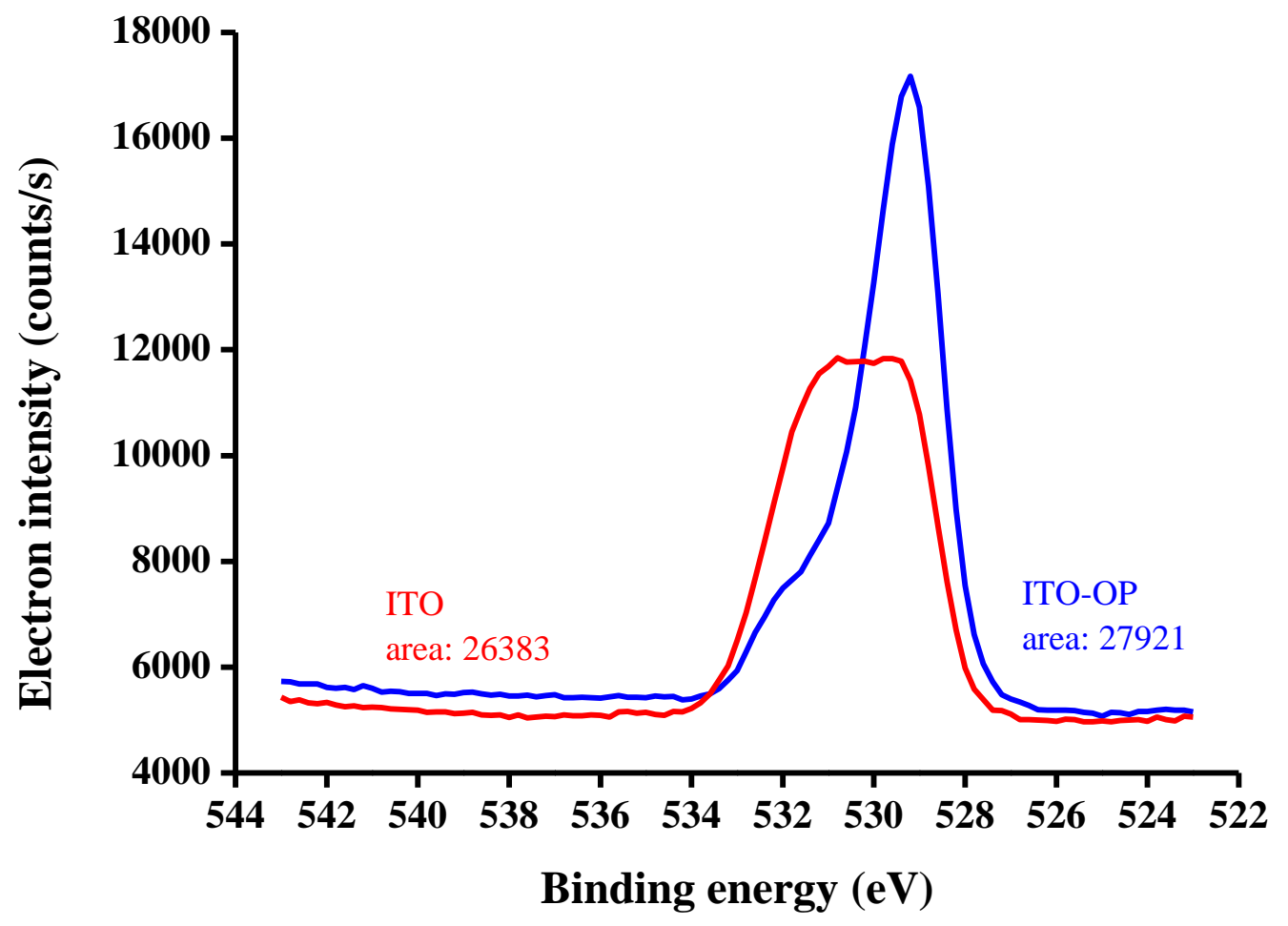

Fig. S1. 


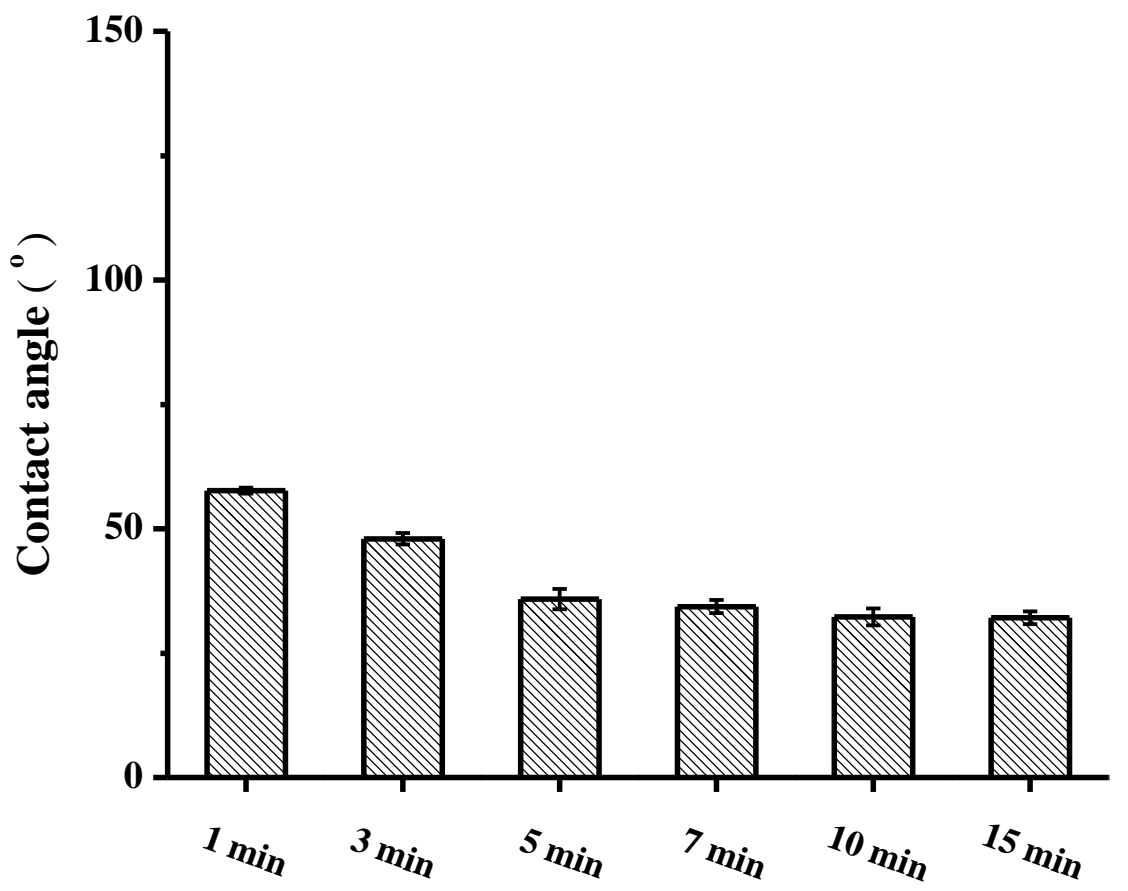

Fig. S2. 


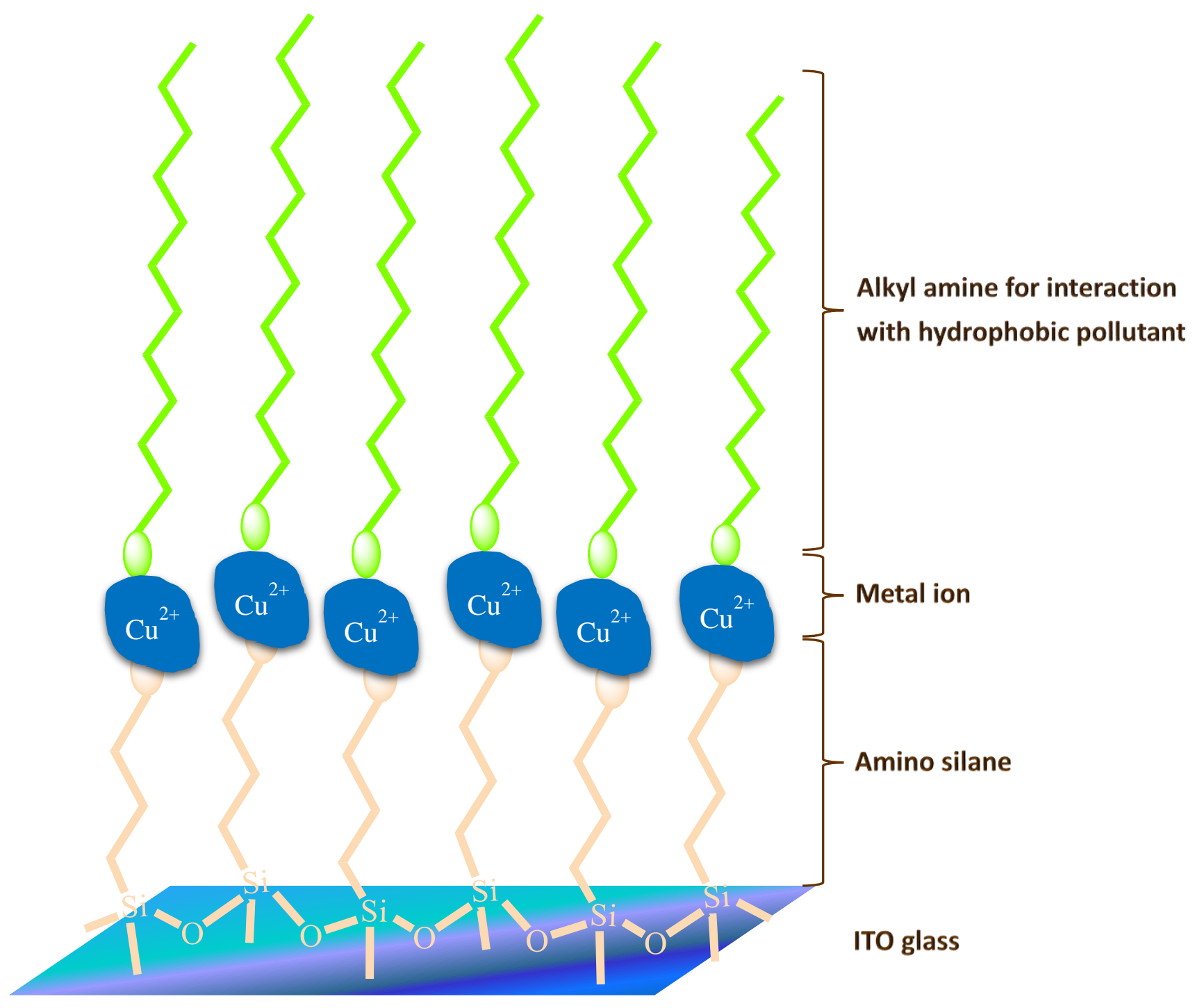

